\title{
Construction d'un référentiel dendrochronologique pour la Basse-Normandie
}

\author{
Vincent Bernard
}

\section{(2) OpenEdition \\ Journals}

Édition électronique

URL : https://journals.openedition.org/adlfi/3733

ISSN : 2114-0502

Éditeur

Ministère de la Culture

Référence électronique

Vincent Bernard, «Construction d'un référentiel dendrochronologique pour la Basse-Normandie »

[notice archéologique], ADLFI. Archéologie de la France - Informations [En ligne], Normandie, mis en ligne le 01 mars 2009, consulté le 22 juin 2021. URL : http://journals.openedition.org/adlfi/3733

Ce document a été généré automatiquement le 22 juin 2021.

(c) ministère de la Culture et de la Communication, CNRS 


\title{
Construction d'un référentiel dendrochronologique pour la Basse- Normandie
}

\author{
Vincent Bernard
}

Date de l'opération : 2009 (PT)

1 La deuxième année d'exercice de ce programme d'étalonnage dendrochronologique de la région Basse-Normandie, encadré par le Service régional de l'archéologie et la Conservation régionale des monuments historiques, aura permis plusieurs avancées importantes. La première, avec le beffroi de la tour nord de la cathédrale de Bayeux (Calvados), consiste dans l'acquisition de données chronométriques majeures pour un édifice unique en France. Cette étude dendro-archéologique aura été, en effet, l'occasion de couvrir presque trois siècles, du Xe $\mathrm{s}$. au XII ${ }^{\mathrm{e}} \mathrm{s}$, , sur une période pour laquelle les références dendrochronologiques sont pauvres et souvent perturbées par des facteurs d'origine anthropique ou climatique. Le beffroi de Bayeux aura donc parfaitement rempli la mission de ce programme en livrant de nouvelles longues séries de cernes, qui serviront à leur tour de référence pour dater de futurs sites historiques et archéologiques. Il a été possible, en outre, de préciser la date de construction de cet édifice à la toute fin du XII ${ }^{\mathrm{e}} \mathrm{s}$. et de mieux saisir les contraintes mécaniques liées au matériau-bois lui-même, depuis sa production jusqu'à sa mise en oeuvre.

2 Ainsi, une nouvelle campagne de prélèvement a été organisée en 2009 afin d'exploiter le maximum de bois d'architecture datable, afin de renforcer le signal dendrochronologique propre à ce site et caler peut-être plus précisément la mise en place de la structure dans une phase romane ou gothique. Les 12 échantillons visaient donc les bois de la structure originelle en place ou réintégrés lors des réaménagements postérieurs dans les quatre pans de bois constituant l'ossature qui supportait les cloches. La chronologie construite regroupe 8 individus et permet de couvrir la période comprise entre 911 et 1192. Ce sont d'ailleurs les références régionales qui nous ont permis d'asseoir cette datation, la chronologie de la cathédrale de Bayeux elle-même, 
mais surtout la chronologie bâtie à partir des pieux de la pêcherie «Boullemer ou Bonnemé 2 ", située à Saint-Pair-sur-Mer dans la Manche (voir Billard et al- PCR "L'exploitation des milieux littoraux en Basse-Normandie »).

3 La suivante concerne les bois archéologiques issus de Bricqueville-la-Blouette (Manche) à l'occasion de la fouille réalisée en 2006 sous la direction d'H. Lepaumier (Inrap) pour le contournement ouest de Coutances. Cette fouille permit rapidement d'établir la présence d'un site fortifié laténien. Deux phases principales ont marqué le développement de cette occupation, la première durant La Tène ancienne, la seconde durant La Tène finale. De tous les éléments en bois qui ont fait l'objet d'une étude xylologique par V. Guitton (Inrap) en 2008, ce sont les deux madriers découverts au fond du fossé 406 ( $2^{\mathrm{e}}$ phase) qui ont retenu notre attention. En effet, ces échantillons comportaient à la fois une cinquantaine de cernes et des aubiers complets ou presque, ce qui semblait favorable à une datation dendrochronologique. En dépit d'une séquence inférieure à 60 cernes, la comparaison visuelle de notre chronologie locale avec les courbes de référence du Grand-Ouest de la France tend à lever toute réserve, tant les corrélations sont de bon niveau. On peut donc établir que cette chronologie couvre la période comprise entre-114 et -66. Compte tenu que les échantillons présentent un aubier de 24 cernes, on peut considérer que la date d'abattage se situe entre -66 et -63 maximum.

4 À la suite d'un diagnostic réalisé en 2004 dirigé par Ch. Colliou (ArkeMine) dans la zone artisanale de Livarot (Calvados), boulevard South Molton, un important site métallurgique occupé aux $\mathrm{I}^{\mathrm{er}} \mathrm{s}$.-II ${ }^{\mathrm{e}} \mathrm{s}$. de notre ère a été identifié. Mais le tronc de chêne subfossile qui a fait l'objet de cette analyse provient d'un paléochenal parallèle au cours de la Vie actuelle. Cent quatre-vingt-douze cernes consécutifs ont pu être mesurés et comparés aux différentes chronologies que nous avons à disposition. En raison de la profondeur de cet élément et dans l'attente d'un résultat de datation radiocarbone, nous avons concentré les recherches de datation sur les périodes pré- et protohistoriques.

5 En raison des hiatus qui jalonnent encore le canevas des références dendrochronologiques pour la Préhistoire dans le nord-ouest de la France, nous ne pouvons nous en tenir qu'au résultat de la datation ${ }^{14} \mathrm{C}$, obtenu à partir du dernier cerne de cet échantillon et situant cette séquence au cours du Bronze final (voir liste cicontre).

6 Au total, ce programme aura permis de financer, via le programme Artemis-culture, la datation radiocarbone de neuf échantillons de bois (échantillons préparés au CDRC à Lyon et analysés au laboratoire de Saclay), afin d'aider au calage des chronologies préhistoriques construites dans le cadre de ce programme et de celui dirigé par C. Billard et portant sur L'exploitation des milieux littoraux en Basse-Normandie. D'ores et déjà, on constate l'ancienneté de certaines séquences, qui appartiennent au Néolithique ancien et moyen, voire peut-être au Mésolithique final, comme dans le cas de troncs issus des Marais de Baupte à Gorges (50), ce qui présente un caractère tout à fait inédit pour le Nord-Ouest de la France.

- Saint-Pair-sur-Mer (50), tourbière littorale

SPM01: $5945 \pm 35$ BP [4930-4725] cal BC

$9 \quad \mathrm{SPM} 02: 5175 \pm 35 \mathrm{BP}[4041-3951] \mathrm{cal} \mathrm{BC}$

SPM03 : $5480 \pm 35$ BP [4360-4264] cal BC 
11

12

\section{AUTEURS}

\section{VINCENT BERNARD}

CNRS

Vincent BERNARD

- Gorges (50), Marais de Baupte (date dendro proposée en 2009 : vers -920)

$01: 5665 \pm 35$ BP [4548-4449] cal BC

$6375 \pm 35$ BP $[5467-5304]$ cal BC

- Livarot (14), Zone Artisanale

$2805 \pm 30$ BP [1014-899] cal BC

- Lingreville (50), Havre de la Vanlée

2009-01 : $3980 \pm 30$ BP [2570-2463] cal BC

2009-02 : $3395 \pm 30$ BP [1748-1621] cal BC

2009-03 : $4225 \pm 30$ BP [2898-2707] cal BC 